\title{
Japan's University Education in Social Sciences and Humanities Under Globalization
}

\author{
Akiyoshi Yonezawa \\ Nagoya University, \\ Japan
}

\section{Introduction}

Japanese society is currently facing high pressure with the structural change of global economics and politics. In 2010, Japan slipped from the $2^{\text {nd }}$ to $3^{\text {rd }}$ in terms of Gross Domestic Product (GDP), replaced by China. In 2011, the biggest earthquake and tsunami in recorded history to hit the Eastern part of this country took place, and was followed by the accident at the Fukushima Daiichi Nuclear Power Plant, which is expected to result in long term damage. Based on its strong social capital, most of the country had already returned to a usual life by the end of 2011. However, the cost for the recovery is adding significant pressure to the national budget, which is already burdened by a huge debt of more than $200 \%$ of its GDP. Faced also with the on-going ageing population phenomena, it is a necessity for Japan to strengthen its linkage with neighbouring countries, most of which are recognized as emerging economies.

Under these circumstances, the Japanese higher education system requires drastic change. On the 21st of November, 2011, the Japanese government implemented a policy review on university reform, and opened up all the discussion and results through an internet-based web-TV system. In the beginning of the discussion, a result of a public opinion poll by Asahi Shimbun was introduced. The data indicated that $63 \%$ of the respondents did not think that Japanese universities could foster globally viable human resources, and $64 \%$ did not think that Japanese universities could foster human resources required by the industry and society. At the same time, the result of the university rankings 2011/2012 by Times Higher Education was also introduced as grounds for questioning the international viability of Japanese universities. In that table, only two out of 780 Japanese universities (the University of Tokyo and Kyoto University) are ranked within the top 100. During the session, social sciences and humanities were treated as a weak point in the international recognition of Japanese university education and research.

Education and research activities in the social sciences, and most especially in the humanities, are by nature highly imbedded in the context of a national language. Except for some specialized academic fields, such as economics and international relationships, faculty members have been trained primarily through post-graduate education in Japan. The main language in which their education and research is conducted is Japanese. Nonetheless, growing trends toward globalization are exerting increasing pressure to transform this linguistic tendency. After the financial crisis in 2008, industry started to request Japanese 
universities to foster 'global human resource' with high-level communication skills in English and other foreign languages. To remain competitive with these international trends, Japanese universities are attempting to adapt to the new global environment.

In the effort to enhance the international viability of Japanese university education in this increasingly globalized arena, the role of quality assurance has become progressively more important. The 'quality' of Japanese higher education, especially in terms of teaching and learning (as opposed to research alone), has long been questioned by observers writing from both within and outside of the country (e.g., McVeigh, 2002; Kinmonth, 2005; Shibata, 2006). It is not sufficient to approach this issue solely from the viewpoint of policy formation, partly because consensus as to what the term 'quality' implies remains elusive (Vroeijenstijn, 1995). Although policy arguments related to the quality of higher education are frequently based on broad impressions formed by the general public, policy and institutional arrangements pertaining to quality assessment and assurance in higher education are best understood when governmental and university administrative processes are taken into consideration.

This article considers the latest initiatives in quality assessment and assurance of education and research activities in Japanese universities, focusing on those systems and procedures having direct bearing on the social sciences and humanities. First, the uncertainty of the position of the social sciences and humanities in quality assessment and assurance in Japanese higher education is introduced, focusing on those social and policy contexts in which academics in social sciences and humanities have been involved. Second, the recent development of the quality assessment and assurance system (and other initiatives for improving the quality of Japanese higher education) is outlined. Third, the author provides the overarching rationale for assessing the quality of research, concentrating on the endeavour of achieving international recognition. Finally, the author points out the particular challenges facing the social sciences and humanities under globalisation.

'Quality assessment' is usually regarded as a tool for assessing performance of public institutions under the policy framework of new public management. On the other hand, 'quality assurance' is also a policy tool for assuring minimum standards of higher education services provided by national, local public, and private higher education institutions under the official recognition of the national government. As of 2011, Japan had 86 national, 95 local-public, and 599 private universities. While acknowledging the efforts of all national, local, and private higher education institutions, the assumptions and conclusions of this article apply mainly to the national university sector. Given their quantitative significance, especially in the field of social sciences and humanities, the author recognizes that private institutions are playing a major role in Japanese higher education.

In 2004, the national government introduced a corporate-style governance system into national universities. This was accompanied by a new evaluation scheme, which was implemented through a collaborative effort by a government committee and a national agency, the National Institution for Academic Degrees and University Evaluation (NIADUE). Most local public universities operated by prefectures and cities have also adopted corporate-style governance, and they face additional pressure from local assemblies to engage in formal performance assessments. In addition, since 2004, the Japanese government has required seven-year, cyclical 'certified evaluations' (accreditation) for all national, local public, and private universities and colleges. This certified evaluation, which is implemented at the institutional level, applies to both new and evolving forms of 
professional post-graduate education programs. Project-based funding schemes, such as the 'Centres of Excellence (COEs)' in research and 'Good Practices,' which are found in various other education programs, are regarded as indirect forms of performance assessment. The Global 30 project, a governmental funding program that support core institutions for providing globally competitive education from 2009, is having a noted impact on the internationalization of top universities.

\section{Context of quality assessment and assurance in Japanese higher education}

The position of the social sciences and humanities in quality assessment and assurance in higher education is uncertain. Most methodological debates for quality assessment, especially those regarding research activities not only in Japan but all over the world, tend to focus more on the fields of engineering, medicine, and the natural sciences. At least four reasons for this focus may be discerned. First, as all countries are inevitably involved in the knowledge economy, it is believed that science and technology-and especially those departments with direct links to industry-are worth investing in to promote national competitiveness in the global economy (Altbach \& Balan, 2007). Second, the usage of quantitative data such as publication numbers and citations is widely accepted in engineering, medicine, and the natural sciences, based on the worldwide development of publication databases and online journals (Leydesdorff, 2001). Third, most natural scientists and engineers feel that the science community is universal: that it is inseparable by national or cultural borders. Approximately $80 \%$ of publications originating from top-level Japanese universities, and $94 \%$ of those from French universities, are written in the English language in the natural science fields (Honda \& Keii, 2004). Finally, the amount of public expenditure and investment from industry that is allocated to the natural and medical sciences and engineering fields is proportionally large. Accordingly, in light of this heavy national investment, institutional claims to 'world class' status and quality assessments to demonstrate efficiency and accountability are inevitably scrutinized by the general public (Yonezawa, 2003).

On the other hand, most social science and humanities fields (excluding those such as economics and business) in highly populated, non-English speaking economies like Japan have been highly protected from international competition. Despite recent, remarkable advances in translation and interpretation technology, language and cultural barriers in academic dialogue through publication and conference presentation continue to represent a great obstacle to the advancement of meaningful international exchange in most social science fields. Moreover, worldwide publication databases in social sciences and humanities (excepting those related to economics) that cover only English publications are not recognized as reliable indicators of research performance, again because of language barriers and the limited number of publications in respective social science fields. Thirdly, the amount of public expenditure for social science and humanities research is small relative to that awarded to the natural sciences, with the former increasingly dependent on the private sector contributions, tuition fees, and consultancy work (Liu \& Cheng, 2007).

However, under increasing pressure to demonstrate public accountability in university activities, academics in the social sciences and humanities have also become engaged in various quality assessment procedures, further contributing to the already intense market competition to attract students and external resources for research, and to establish consultancy relationships. 
It is important to consider the particular significance of quality assessment and assurance to the social science and humanities fields in Japanese universities. First, academics in social sciences and humanities are obviously making a key contribution to human resource development as well as research. Full-time faculty members in the social sciences and humanities comprise $27.6 \%$ of all full-time academic staff at Japanese universities (MEXT, 2007). Considering the quantitative significance of the number of students in the social sciences and humanities stated as a share of total student bodies $-49.2 \%$ in undergraduate, $36.5 \%$ in post graduate programmes-this would appear to represent a considerable contribution indeed (MEXT, 2011).

Fundamental problems related to the internationalisation of non-English speaking academic communities are also more visible in the social sciences and humanities. Teichler (1999) described the internationalisation of higher education in developed, non-English speaking countries with strong national identities such as France and Japan as 'internationalisation in two arenas'. In the case of Japan, universities are faced with internationalization issues in (1) expanding the international influence of its education and research in the Japanese language, as well as (2) helping to adjust its domestic academic community to English-based, international academic dialogue. In terms of publication and promotion, Japanese academics continue to be subject to the forces of inherent customs, rules, and values quite different from those of English speaking countries (Eades, 2000; 2001; 2004). In light of rapidly increasing pressure related to the globalisation of the academic community, as well as the society in which they live, academics in social sciences and humanities in Japan face the dilemma of pursuing two opposing courses to reach the goals of domestic and international prestige in research, and sometimes also in education. Here, quality issues for academics for social sciences and humanities are inevitably linked with the issue of internationalisation.

\section{Recent developments in quality assessment and assurance in Japanese higher education}

The history of quality assessment and assurance in Japanese universities begins with the establishment of the Japan University Accreditation Association (JUAA, or Daigaku Kijun Kyokai) in 1947, which was modelled after the US accreditation system. The JUAA defines itself as a 'voluntary' association through the initiatives of universities, and its Board of Trustees and Auditors is comprised of university representatives. In reality, however, it is well known that JUAA was established under the initiative of the US military authority that occupied Japan from 1945 to 1950, and aimed at depriving the Monbusho (Ministry of Education) of control over universities (Tsuchimochi, 1993). Therefore, the mission of JUAA at that time was to place importance on autonomous quality assurance and improvement as initiated by the universities themselves. Under the social confusion of the immediate post-war period, however, most newly-established universities, and even older institutions with a pre-war history, faced a significant lack of human and physical resources to meet standards set by JUAA.

In 1956, the Ministry of Education initiated its own governmental authorization procedure based on its Standards for the Establishment of Universities (Kimura, Yonezawa, \& Ohmori, 2004). JUAA continued its voluntary-based accreditation scheme until the beginning of the 1990s, while quality assessment was implemented only once with each institution as a condition for obtaining membership in the association (Baba \& Hayata, 1997). While governmental authorization and standards were considerably strict and detailed, there was 
no effective system to monitor quality once universities and their programmes were authorized (MEXT Higher Education Bureau, 2006).

In short, the main concern in terms of 'quality' up until the 1980s had been the maintenance of minimum standards to qualify as 'universities' that were recognized by 'peers' of existing institutions both inside and outside of Japan. Continuous 'over-demand' for university enrolment led to a situation whereby the status of 'universities' was highly protected not by the quality of research and educational activities, but by limited enrolment opportunity. Dore (1997) characterized this era of highly competitive entrance examination procedures and inflated university prestige as 'Diploma Disease'. Despite this, industry had not yet come to rely on the quality of university educational programmes in general (Yonezawa \& Kosugi, 2006). Former president of the electronics giant, Sony, Akio Morita, wrote a critical argument that Japanese higher education and schooling are useless, representing the voice of Japanese industry, which had come to rely on high level, in-house training (Morita, 1987).

By the 1980s, and the culmination of Japan's 'bubble economy', the trend of policy arguments had completely changed from 'welfare state policy' to 'neo-liberalism policy', partly influenced by international trends in the US and Europe, which in this period were experiencing economic depression after the oil shocks of the early 1970 s.

The European example is largely credited for having activated the 'accountability' debate in Higher Education. Neave (1988; 1998), utilising his term 'evaluative state', noted that (Western) European countries started to introduce external quality assessment systems and forms of institutional management autonomy to higher education as new and indirect means for state governments to control universities. These European initiatives and the general discussion of neo-liberal arguments applied to the Education fields, activated debate in Japan over university evaluation. In the UK, before 1992, the basic university authorisation process assumed the form of 'Charters' which were directly granted by the King or Queen; however, an effective system to assess the quality of education and research on a regular basis was lacking. Near the end of the 1980s, new quality assessment initiatives in the UK, France, and the Netherlands were spread throughout Western Europe during the 1990s, and all over the world during 2000s. However, as of the early part of the 1990s, opinion leaders in Japan were arguing that the nation should follow the US non-governmental, voluntary-based cyclical accreditation model rather than prevailing European examples.

As Neave (1988) suggested, the process of introducing quality assessment and evaluation as a new tool of indirect control by the nation-state tends to be accompanied by the deregulation of university standards set by governments, with the aim of strengthening the management capacity of higher education institutions. In 1991, the Standards for University Establishment were drastically simplified, in order to give more flexibility, or room, for innovation in higher education programmes through initiatives of respective governments. As part of this streamlining effort, the government now required that universities and colleges make efforts towards self-monitoring and self-evaluation in order to demonstrate public accountability and foster the management capacity of universities (Kitamura, 1997). However, the governmental arrangement of an external or third-party evaluation system was not introduced at this time, and evaluation was left to volunteer-based initiatives of universities. Here, JUAA was expected to take a more active role as an external quality assessment body; accordingly, the organization started a re-accreditation process of existing members. By 1997 , more than $80 \%$ of 
universities had implemented some form of standardized self-monitoring and evaluation (Shimizu, Baba, and Shimada, 2000; Yonezawa, 2002).

In reality, under the economic prosperity of the 1990s, the pressure on Japanese universities to show accountability was not as imminent as the pressure on those in some Western European countries such as the Netherlands and the UK. However, from the mid-1990s, after the Japanese economy entered into a serious economic recession, pressure on national universities to implement administrative reform strengthened. Aiming for a drastic reduction of the number of national civil servants and the national budget, prominent economists, as well as officials of the Ministry of Finance (MOF), started to argue for the possible privatisation of national universities. Although this privatisation was ultimately not realized, faced with strong resistance from the national universities, pressure to show accountability became much stronger than before. In order to accelerate administrative reform within the national university system, the University Council (Daigaku Shingi Kai), the ministerial advisory body for university policies, recommended the introduction of 'third party evaluation' to assess institutional performance, and that the results of these assessments be considered in deciding national university budgets.

Based on the above recommendations of University Council, the National Institution for Academic Degrees and University Evaluation (NIAD-UE: Daigaku Hyoka Gakui Juyo Kiko) began conducting third party evaluations, first as pilot schemes with a limited number of participating institutions appointed by the Ministry of Education, Culture, Sports, and Technology (MEXT: Monbu Kagaku Sho). This pilot university evaluation program was implemented from 2000 to 2003, to (1) evaluate all national universities according to selected themes, such as international linkages and social contributions, (2) evaluate education activities in all fields, and (3) evaluate research activities in all fields.

In 2004, national universities introduced a corporate-style governance scheme with medium-term (six year) goals and plans (Hirowatari, 2000; Oba, 2007). In addition to their present obligation to submit annual reports, NIAD-UE will assess the teaching and research performance of these institutions every six years and submit results to the National University Corporation Evaluation Committee (NUCEC, Kokuritsu Daigaku Hojin Hyoka Iinkai), a subcommittee within MEXT that evaluates mainly the managerial aspects of national university corporations. The NUCEC will publish its evaluation report as informed by the results of NIAD-UE's quality assessment. The results of the evaluation are to be considered by MEXT, and utilized for budgetary purposes in subsequent six year cycles. As previously mentioned, many local public universities were also transformed into independent administrative corporations under the supervision of local governments. These local governments sometimes require similar external evaluation of their own universities: for example, certified evaluation by JUAA, NIAD-UE, or JIHEE.

As a part of the third-party evaluation scheme, 'certified evaluation' (accreditation) became compulsory for all national, local-public, and private universities, junior colleges, or colleges of technology from 2004. Certified evaluation consists of (1) institutional accreditation and (2) accreditation of professional post-graduate programmes (MEXT Higher Education Bureau, 2006). Adding to JUAA and NIAD-UE, the Japan Institution for Higher Education Evaluation (JIHEE: Nihon Koto Kyoiku Hyoka Kiko) was established by the Association of Private University of Japan (APUJ: Nihon Shiritsu Daigaku Kyokai) to implement certified evaluation mainly for private member universities. 


\section{Means and objectives of assessing the quality of teaching and learning}

Teaching and learning are at the core of the quality assessment of university activities. However, methodologies of assessing the quality of these functions are still in the primary stages of development. In general, any assessment scheme of teaching and learning will assess the input, process, output (direct achievements), and outcomes (indirect and long-term effects) of teaching and learning. Each university, and, in many cases, each programme, has different objectives or missions. As part of the admissions process, institutions or programmes should disseminate a clear mission statement detailing their teaching and learning activities among applicants and newly enrolled students. Curriculum and learning support systems should be consistent with those objectives, and outcomes should be monitored as the basis for constructive feedback for better teaching and learning. However, accurately assessing the quality of output and outcomes is very difficult, especially if their relationship with the initial teaching and learning objectives is uncertain. In the US and Europe, retention and pass rates could serve as clear performance indicators. However, in the Japanese case, retention rates are so high (around 90\%), and the academic performance within the enrolment level so diverse that these can hardly serve as 'objective' indicators by which to assess output and outcomes. This is mainly due to the drastic transformation of the Japanese higher education market from a long-term, over-demand condition until the beginning of 1990s, to the present over-supply condition. While high retention rates used to be combined with the assurance of minimum academic achievement at the enrolment in the universities, this is no longer the case.

There are mainly two types of quality assessment: (1) threshold type assessment, aimed at assuring minimum standards; and (2) quality or performance assessment, used for rating or ranking purposes. Accreditations and university evaluation standards are examples of the former type, and the National University Corporation Evaluation Plan is an example of the latter type.

Certified Evaluation (2004 - present). Certified Evaluation is a third-party process that could be understood as a form of accreditation. The main objectives of certified evaluation are quality assurance, quality improvement, and accountability of universities and colleges at both the institutional and programme levels. Programme-level certified evaluation is required only for professional post-graduate programmes that have recently been established and are separate from traditional, academic-oriented post-graduate programmes. Certified evaluation is implemented by third-party evaluation organisations, which are certified by the government through approval by an advisory committee under published guidelines requiring transparency and fairness in the evaluation process.

Universities and colleges choose from among different 'certified' evaluation organisations, and submit findings of the quality assessment process once every seven years for institutional evaluation, and once every five years for professional post-graduate programmes. As for the institutional-level certified evaluation, JUAA, NIAD-UE, and JIHEE have already published initial evaluation reports of almost all universities and colleges by 2011. Some did not meet the requested standards, and underwent additional monitoring or re-submission. As for the certified evaluation of professional post-graduate programmes, evaluation organizations in prospective fields have been certified. Certified evaluation organisations publish the standards and processes of evaluation in manuals for both reviewers and the higher education institutions being reviewed. Based on these guidelines, universities and colleges are required to submit self-evaluation reports. The review committee reads self-evaluation reports, 
implements site visits, and publishes final observations. Universities and colleges have an opportunity to make objections, to which the certified evaluation organisations respond. Each certified evaluation organisation exhibits some uniqueness in their guidelines and evaluation processes, although general characteristics are almost the same under the government-set guidelines for certification. All certified evaluation organisations attempt to respect the missions and goals of individual universities and colleges, while they also try to assure that minimum standards are present in each consideration.

National University Corporation Evaluation (Plan). The incorporation of national universities was presented and accepted as a tool for assuring institutional autonomy for university-led reforms. However, in the process of implementing the National University Corporation Act and related regulatory schemes, it came to light that the National University Corporation Scheme would be implemented as an application of the Independent Administrative Corporation (IACs: Dokuritsu Gyosei Hojin) Scheme, which was applied to organisations implementing government public services. The purpose of IAC quality assessment is basically to promote the effective use of public resources by assessing performance as well as accountability. Therefore, from a governmental point of view, the quality assessment of any national university corporation should be designed as a type of performance assessment to determine budgetary allocations and be persuasive enough for the Ministry of General Affairs (Somusho), Ministry of Finance, and the general public.

In other words, medium-term goals and purposes are regarded as a contract between 'autonomous' universities and the government. Alternatively, they might be viewed by universities as declarations of the corporate strategies of national university corporations, or by the government as achievement plans of public service organisations. These two perspectives consistently arise in the dialogue concerning the design and direction of the National University Corporation Evaluation Plan. Philosophies and mission developed by each university are stated and written within the recommendation reports.

The evaluation of educational activities will be implemented as follows. Each national university faculty or school is first required to submit the reports on its educational activities. Next, evaluation committees set up by prospective disciplines assess the submitted basic data and give ratings based on 'the system for implementing educational activities', 'educational contents', 'educational methods', 'achievement of learning', and 'students' careers after graduation'. The committees then rate the degree of quality improvement in educational activities based on concrete examples of educational reforms. If necessary, the committees may implement site visits to universities. In January, 2011, the first quality assessment report by NIAD-UE was submitted to the National University Corporation Evaluation Committee of the MEXT. All the reports are published with ratings through the internet.

Adding to these quality assessment systems is the non-governmental scheme on developing Reference Benchmarks of University Education by the Science Council of Japan (SCJ). The practice of establishing benchmarks for reference in university education in prospective disciplines was first implemented in the UK. In the UK, the Quality Assurance Agency (QAA) had previously implemented subject level quality assessment in university education. However, based on strong opposition by the universities, this scheme was terminated in 2001 (QAA 2003). Instead, the QAA started a project to establish benchmarks for reference ('subject benchmarking') in prospective subjects such as history and physics. In this model, each university has a responsibility to set up an internal quality assurance system to assure the quality of its education with reference to the benchmarks. Following 
this model, SCJ started to establish such reference benchmarks for 30 disciplines in 2010 (Science Council of Japan, 2010).

\section{Means and objectives of assessing the quality of research}

Quality assessment of research activities in Japanese universities is a widely and actively debated subject among university faculty members, staff, and students alike. Especially in fields with well-developed citation databases, bibliometrics, and other quantitative approaches for assessing research, activity and quality are often discussed. A citation database of Japanese research papers has also been developed (Negishi, Sun, \& Shigi, 2004). International publication databases are commonly used in the field of economics, and the Social Sciences Citation Index is also becoming popular. However, by their very nature, most of the social sciences and humanities are not well suited to these quantitative approaches, and the peer evaluation system is regarded as the only choice when it comes to reliable assessment.

Some social science and humanity fields tend to face difficulty in arriving at a consensus among reviewers with different academic or, sometimes, political inclinations. Most articles in the social sciences in Japan are written in Japanese, and therefore assessors are almost always limited to Japanese authors, or others who are committed deeply to the Japanese academic community.

The impact of the '21st Century Centres of Excellence' programme and the following 'Global Centres of Excellence' programme on the social sciences and humanities in Japan have been significant both at the national and the institutional-level selection process. Eades (2005) argues that human science projects of COE faced difficulty in demonstrating research performance at the interim stage of review, receiving pressure from natural science fields being assessed by 'international standards'. At the institutional level, the offices of university presidents were required to assemble and prioritize their research units prior to submitting COE proposals. Here, straightforward discussion to assess the quality of research between and among different fields often took place, in order to determine priority among programs and projects (for example, between a research project in social theory and another in chemical engineering). Again, at least among top national universities, it is not easy for research groups from the humanities and social sciences to be given high priority. Historically, offices of university presidents did not possess accurate information on academic performance among different faculties and departments. The internal selection process of such projects now gives presidents' offices greater power to access this information for prioritizing and other management purposes.

It is worth recalling that the $21^{\text {st }}$ Century COE scheme represented the refinement of a previous plan to foster the 'top 30 world-class research universities' (Yonezawa, 2003). However, the results of this earlier initiative merely served to reproduce, and even reinforce, the existing domestic hierarchical order among Japanese universities, based on domestically implemented 'peer reviews' conducted in the Japanese language (Yonezawa, 2007). The Global COE programme, which replaced the 21st Century COE programme in 2007, introduced peer review conducted at least in part in the English language. Also in 2007, the Japan Society for the Promotion of Science (JSPS: Research Council of the Japanese government) initiated a new programme called the 'World Premier International Research Centre Programme' for investing more than the COE programme into a highly limited number of research projects for the coming 10 to 15 years. Under this programme, a full- 
scale international peer review, based both in Japanese and English, was implemented. This addition of bilingual peer review did not lead to any project in humanities and social sciences being selected. From 2011, a new funding program called 'Leading Doctoral Programme' started to support launching internationally competitive doctoral programs. However, the assessment procedure was implemented only in Japanese, and only one of the 21 selected programmes was from the social sciences: 'The Program for Cross-Border Legal Institution Design' of Nagoya University.

Within the National University Corporation Evaluation Plan, NIAD-UE assessed the quality-level and quality-improvement of research activities, and the final result was published in 2011. Each faculty or school of national universities was required to submit a 'report on excellent research achievements which represent schools and faculties' and a 'report on strategically-focused research achievements in the field' to committees of NIADUE. Committees organised by respective fields then analysed and assessed the reports, and implemented site visits if necessary. When deciding ratings, the original missions and purposes of each university are to be respected and taken into consideration. Attached to the Certified Evaluation scheme, NIAD-UE started optional services for the quality assessment of research activities mainly of local-public and private universities.

Especially in regards to the quality assessment of research activities, there is a widespread suspicion that reported research performance will be utilized for financial allocation. Although the research performance indicators did not have a significant impact on the financial allocation by the MEXT in the end (Yonezawa, 2011), the published assessment result became useful information in setting up a management and financial strategy at the university level.

\section{Pressures for the globalization in social sciences and humanities}

The impact of globalization has intensified over the last decade. Faced with the robust socioeconomic development in East Asia and other regions, as well as substantial regional integration in Europe and ASEAN, Japanese society itself is at the crossroads. At the same time, experiencing a struggle for recovery from the disasters in March, 2011, Japanese universities have become more seriously committed to the networking and collaborative efforts both internally and internationally.

How to improve the quality of university education and research is still a highly controversial question, especially within the humanities and social sciences. In terms of pedagogical practice, a long tradition of teacher-centred instruction is now transformed into more student-centred learning styles. The University of Tokyo invited Michael Sandel from Harvard University to demonstrate interactive lectures, and the NHK, the public broadcast company, broadcast the lectures on TV in a series.

The government has also tried to promote the good practices of teaching improvement and faculty development activities through various incentive funds. 'Faculty developers', new professionals who are engaged in the teaching improvement activities, launched their own network in collaboration with their international community.

Market mechanisms may also have a strong influence in quality improvement in the social sciences. Students choose universities, at least in part, based on prestige, quality of services, rankings, and other similar status indicators. Employers have some preferences as to graduates of certain institutions, and the rankings of those employers are also provided to 
the media. Particularly for less prestigious private universities facing applicant shortages, the impact of market mechanisms is significant (Doi, 2007; Yonezawa \& Kim, 2008). However, as many observers have already pointed out, unpopular private universities are aiming solely to fill student seats, regardless of readiness for higher learning. This almost corrupt educational environment illustrates that market competition does not always assure the quality of university education (Kinmonth, 2005).

Here, the issue of university education became more widely recognized as an issue of human resource development. In 2007, the Ministry of Economics, Trade, and Industry (METI) published a report to request university education to provide basic skills necessary for the working life among the graduates (METI, 2007). In 2010, the METI developed another report to stress the necessity of fostering 'global human resources' (Global Human Resource Development Committee of the Industry-Academia Partnership for Human Resource Development, 2010). In their definition, global human resources should have (1) fundamental competencies for working persons, (2) communication ability in a foreign language (particularly in English, which is widely used globally), and (3) ability to understand and take advantage of different cultures. Following the report, Keidanren (Japan Business Federation) and the MEXT also published a proposal and report with similar themes (Keidanren, 2011, Sangaku Renkei niyoru Global Jinzai Ikusei Suishin Kaigi, 2011).

At the same time, the government, as well as universities, became aware of the importance of student exchange, as well as internalization at home through accepting international students. In 2008, the Japanese government started a plan to invite 300,000 international students by 2020. In 2010, the new government, led by the Democratic Party Japan (DPJ), added the policy plan to send 300,000 Japanese students abroad for fostering global human resources (Prime Minister of Japan and his Cabinet, 2010).

In 2009, 13 top comprehensive universities were selected in a project, 'Global 30', for supporting internationally viable university education (Yonezawa 2011). They launched degree programs in the English language both at undergraduate and graduate levels. They are also encouraged to hire international faculty members for promoting quality education in the English language for students coming from all over the world. Nagoya University, one of the selected top national universities offers such programs in social sciences, natural sciences, and engineering. Interestingly, the social sciences program is most popular among the international applicants, probably because the attractiveness to study in Japan is much more connected with the attractiveness of Japanese society itself, at least at the undergraduate level.

Student exchanges, including double degree programs with foreign partner universities, are also becoming popular. In order to assure the quality of those joint education programs with foreign universities, the MEXT set up a guideline to recommend careful design of curricula through intensive discussion with partner universities (Central Council for Education Working Group on the Promotion of Globalizing Universities, 2010). At the same time, the MEXT launched a programme, 'Re-Inventing Japan Project', for promoting student exchange under partnership with universities in the US, China, South Korea, and other countries. This program is divided into Type A (partnership mainly with China, South Korea and South East Asian Countries) and Type B (partnership mainly with US and other western countries). Nine out of the 13 selected programs in Type A, and six out of the 12 selected programs in 2011 could be categorised as the programmes in the field of social sciences and humanities. 
It is obvious that social sciences and humanities in general have been in a disadvantageous position to partake in the money game in on-going quality assessment and assurance policies in higher education. However, the pressures of globalization, especially in terms of human resource development, are providing a great opportunity for social sciences and humanities to revitalize themselves, not least by internationalizing their profile.

Academics and experts in social sciences and humanities have a great responsibility for the future direction of Japanese higher education policy and the future destination of the social sciences and humanities in Japan. What social sciences and humanities can contribute to society should be demonstrated through autonomous peer initiative, including the formulation of a quality assessment scheme, which could serve as a good model for other fields. At the same time, both international communities and the Japanese general public are becoming intolerant of further delays in increasing international competitiveness.

\section{Notice}

This article is partly based on the author's article 'Quality Assessment and Assurance in Japanese Universities: The Plight of the Social Sciences'. Social Science Japan Journal, 11(1), 2008.10, 69-82.

\section{References}

Altbach, Philip G. \& Jorge Balan eds. (2007). World Class Worldwide: Transforming Research Universities in Asia and Latin America. Baltimore: Johns Hopkins University Press.

Amano, I. \& Poole, G. S. (2005). "The Japanese university in crisis", Higher Education 50-4: 685-711.

Baba, M. \& Hayata, Y. (1997). "The changing role of JUAA in Japanese university evaluation", Assessment \& Evaluation in Higher Education. 22(3): 329 - 335.

Cavalli, Alessandro ed. (2007). Quality Assessment for Higher Education in Europe, London: Portland Press.

Central Council for Education Working Group on the Promotion of Globalizing Universities (2010). Guidelines for Building Organized and Continuous Cooperation Including Double and Joint Degree Programs. Tokyo: MEXT.

Cutts, R. L. (1997). An Empire of Schools: Japan's Universities and the Molding of a National Power Elite. New York: M.E. Sharpe.

Doi, R. (2007). Daigaku ga Teikyo Suru Kyoiku Kenkyu ni Kakawaru Kyoso Kankyo ni Kansuru Kozo teki Bunseki [Structural analyses on competitive environment related to education and research provided by universities]. RIETI Policy Discussion Paper 07-P-003.

Dore, R. (1997). The Diploma Disease: Education, Qualification and Development: 2nd ed. London: Institute of Education, University of London.

Eades, J. S. (2000). "Why don't they write in English?" Academic modes of production and academic discourses in Japan and the West. Ritsumeikan Journal of Asia Pacific Studies 6, 58-77.

Eades, J. S. (2001). "Reforming Japanese higher education: Bureaucrats, the birth rate, and visions of the 21st century". Ritsumeikan Journal of Asia Pacific Studies 8, 86-101.

Eades, J. S. (2004). "Local research, global audiences: Linguistic hegemony and transnational publishing in the information age". In P.J. Matthews \& J. Akamine (eds). Research writing in Japan: Cultural, personal and practical perspectives. Osaka: National Museum of Ethnology. 
Eades, J. S. (2005). “The Japanese 21st COE center of excellence program: internationalization in action?". in Eades, J.S., Roger Goodman, \& Yumiko Hada, 2005, The 'Big Bang' in Japanese Higher Education. Melbourne: Trans Pacific Press. 295-323.

Eades, J. S., Goodman, R. \& Hada, Y. (2005), The 'Big Bang' in Japanese Higher Education. Melbourne: Trans Pacific Press.

Global Human Resource Development Committee of the Industry-Academia Partnership for Human Resource Development (2010). Develop Global Human Resources through Industry-Academia-Government Collaboration. Tokyo: METI [in Japanese].

Hall, I. P. (1998). Cartels of the Mind. New York: North.

HEFCE. (2007). Research Excellence Framework: Consultation on the assessment and funding of higher education research post-2008.

Hirowatari, S. (2000). "Japan's national universities and dokuritsu gyousei houjin-ka". Social Sciences Japan 19: 3-7.

Honda, T. \& Keii, T. (2004), "Shizen Kagaku Kei no Kenkyu Hyoka” [Research Assessment for Natural Science]. Daigaku Ronshu, 35: 403-418.

Kaneko, M. (2002). "Hyoka Shugi no Kanpei" [A pitfall of evaluation-ism], KyoikugakuNenpo 9: 71-94.

Kawaguchi, A. (2006). Daigaku Hyoka Bunka no Tenkai [Evolution of Evaluation Culture at Universities], Tokyo: Gyosei.

Keidanren (2011). Global Jinzai no Ikusai ni muketa Teigen [Proposals for Fostering Global Human Resources]. Tokyo: Keidanren.

Kimura, T., Yonezawa, A. \& Ohmori, F. (2004). "Quality assurance and recognition of qualifications in higher education: Japan", OECD, Quality and Recognition in Higher Education: The Cross-border Challenge, Paris: OECD 119-130.

Kinmonth, E. H. (2005). "From selection to seduction: the impact of demographic change on private higher education in Japan', in Eades, J.S., Roger Goodman and Yumiko Hada, 2005, The 'Big Bang' in Japanese Higher Education. Melbourne: Trans Pacific Press. 106-135.

Kita, H. \& Ida, Masaaki. (2003). "University evaluation and university information system”, Research in University Evaluation 3: 5-20.

Kitamura, K. (1997). "Policy issues in Japanese higher education", Higher Education, 34-2. $141-150$.

Kitamura, K. (2002). Daigaku ha Umare Kawareru ka (Reborn of Universities or Not?), Tokyo: Chuko Shinsho.

Leydesdorff, L. (2001). The Challenge of Scientometrics: the Development, Measurement, and Selforganization of Scientific Communications [2nd ed.], Macquarie Park: Universal Publishers.

Liu, N. C. \& Cheng, Y. (2006). “Academic rankings of world universities: methodologies and problems", Sadlak, Jan and Liu Nian Cai eds. The World-Class University and Ranking: Aiming Beyond Status. Bucharest: UNESCO-CEPES.

McVeigh, B. J. (2002). Japanese Higher Education as Myth. Armonk, N.Y.: M.E. Sharpe.

METI (2007). Shakaijin Kiso Ryoku Ikusei no Susume [Promotion for the Baskic Skill Development for Working Life]. Tokyo: METI.

MEXT (2007). School Teachers' Survey. (http://www.mext.go.jp/b_menu/toukei/chousa01/kyouin/1268573.htm)

MEXT (2011). School Basic Survey. (http://www.mext.go.jp/b_menu/toukei/chousa01/kihon/1267995.htm)

MEXT Higher Education Bureau (2006), OECD Thematic Review of Tertiary Education: Country Background Report of Japan.

Morita, A. (1987). Gakureki Muyoron [Uselessness of Academic Diplomas]. Tokyo: Asahi Shimbun. 
Neave, G. (1988). “On the cultivation of quality, efficiency and enterprise: an overview of recent trends in higher education in Western Europe, 1986-1988", European Journal of Education, 23 (1/2): 7-23.

Neave, Guy. (1998). "The Evaluative State Reconsidered", European Journal of Education, 33(3): 265-84.

Negishi, M., Sun, Y. \& Shigi, K. (2004). “Citation database for Japanese papers: A new bibliometric tool for Japanese academic society", Scientometrics. 60 (3): 333-351.

Oba, J. (2007). "Incorporation of National Universities in Japan", Asia Pacific Journal of Education 27-3: 291 - 303.

Prime Minister of Japan and his Cabinet (2010). New Growth Strategy - Strong Economy, Robust Public Finances \& Strong Social Security System. Tokyo: Prime Minister of Japan and his Cabinet.

QAA (2003). Learning from subject review 1993-2001. Gloucester: QAA.

Sangaku Renkei niyoru Global Jinzai Ikusei Suishin Kaigi (2011). Sangakukan ni yoru Global Jinzai Ikusei no tameno Senryaku [Strategies for Global Human Resource Development through the linkage among Industry, Academics and Government]. Tokyo: MEXT.

Schwarz, Stefanie and Don F. Westerheijden eds. (2004). Accreditation and evaluation in the European higher education area. Dordrecht: Kluwer Academic Publishers.

Science Council of Japan (2010). Daigaku Kyoiku no Bunya Betsu Shitsu Hosho no Arikata nitsuite [On Subject level Quality Assurance of University Education]. Tokyo: Science Council of Japan.

Shimizu, K., Baba, M., \& Shimada, K. (2000). "The new role of the JUAA in Japanese university evaluation". Assessment \& Evaluation in Higher Education 25 (1): 51-60.

Teichler, U. (1999). "Internationalisation as a challenge for higher education in Europe". Tertiary Education and Management 5:5-23.

Tsuchimochi, G. H. (1993). Education Reform in Postwar Japan : the 1946 U.S. Education Mission. Tokyo: University of Tokyo Press.

Vroeijenstijn, A.I. (1995). Improvement and Accountability: Navigating Between Scylla and Charibdis. London: J. Kingsley Publishers.

Yonezawa, A. (2002). “The quality assurance system and market forces in Japanese higher education". Higher Education 43: 127-139.

Yonezawa, A. (2003). "Making 'World-class Universities': Japan's Experiment". Higher Education Management and Policy. 15 (2): 9-23.

Yonezawa, A. (2004). "Daisansha Hyoka Kikan no Seikaku to Yukosei" [Characteristics and Effectiveness of Third-Party Evaluation Organizations]. Yamanoi, Atsunori and Kazuhiko Shimizu, eds. Daigaku Hyoka no Tenkai [Development of University Evaluation], Tokyo: Toshindo. 267-290.

Yonezawa, A. \& Kosugi, R. (2006). “Education, training, and human resources: meeting skill requirements", Tsutomu Shibata ed. Japan: Moving toward a More Advanced Knowledge Economy. Washington D.C.: World Bank Institute 105-126.

Yonezawa, A. \& Kim, T. (2008). The Future of Higher Education in the Context of a Shrinking Student Population: Policy Challenges for Japan and Korea. Higher Education to 2030, 1, 199-220, OECD.

Yonezawa, A. (2011). The "Global 30" and the consequences of selecting "world-class" universities in Japan, In Nian Cai Liu, Qi Wang, \& Ying Cheng (eds.), Paths to a World Class University, Rotterdam: Sense Publishers. 67-81. 
(C) 2012 The Author(s). Licensee IntechOpen. This is an open access article distributed under the terms of the Creative Commons Attribution 3.0 License, which permits unrestricted use, distribution, and reproduction in any medium, provided the original work is properly cited. 